\title{
Electroacupuncture Reduces Cocaine-Induced Seizures and Mortality in Mice
}

\author{
Yi-Hung Chen, ${ }^{1}$ Boris Ivanic, ${ }^{1,2}$ Chieh-Min Chuang, ${ }^{1}$ Dah-Yuu Lu, ${ }^{3}$ and Jaung-Geng Lin ${ }^{4}$ \\ ${ }^{1}$ Graduate Institute of Acupuncture Science, China Medical University, Taichung 40402, Taiwan \\ ${ }^{2}$ Children's University Hospital, Limbova 1, Bratislava, Slovakia \\ ${ }^{3}$ Graduate Institute of Neural and Cognitive Sciences, China Medical University, Taichung 40402, Taiwan \\ ${ }^{4}$ School of Chinese Medicine, China Medical University, Taichung 40402, Taiwan
}

Correspondence should be addressed to Yi-Hung Chen; yihungchen@mail.cmu.edu.tw and Jaung-Geng Lin; jglin@mail.cmu.edu.tw

Received 9 January 2013; Accepted 17 February 2013

Academic Editor: Gerhard Litscher

Copyright ( 2013 Yi-Hung Chen et al. This is an open access article distributed under the Creative Commons Attribution License, which permits unrestricted use, distribution, and reproduction in any medium, provided the original work is properly cited.

\begin{abstract}
The aims of this study were to characterize the protective profile of electroacupuncture (EA) on cocaine-induced seizures and mortality in mice. Mice were treated with EA $(2 \mathrm{~Hz}, 50 \mathrm{~Hz}$, and $100 \mathrm{~Hz})$, or they underwent needle insertion without anesthesia at the Dazhui (GV14) and Baihui (GV20) acupoints before cocaine administration. EA at $50 \mathrm{~Hz}$ applied to GV14 and GV20 significantly reduced the seizure severity induced by a single dose of cocaine $(75 \mathrm{mg} / \mathrm{kg}$; i.p.). Furthermore, needle insertion into GV14 and GV20 and EA at $2 \mathrm{~Hz}$ and $50 \mathrm{~Hz}$ at both acupoints significantly reduced the mortality rate induced by a single lethal dose of cocaine $(125 \mathrm{mg} / \mathrm{kg}$; i.p.). In the sham control group, EA at $50 \mathrm{~Hz}$ applied to bilateral Tianzong (SI11) acupoints had no protective effects against cocaine. In addition, EA at $50 \mathrm{~Hz}$ applied to GV14 and GV20 failed to reduce the incidence of seizures and mortality induced by the local anesthetic procaine. In an immunohistochemistry study, EA (50 Hz) pretreatment at GV14 and GV20 decreased cocaine (75 mg/kg; i.p.)-induced c-Fos expression in the paraventricular thalamus. While the dopamine $\mathrm{D}_{3}$ receptor antagonist, SB-277011A (30 mg/kg; s.c), did not by itself affect cocaine-induced seizure severity, it prevented the effects of EA on cocaine-induced seizures. These results suggest that EA alleviates cocaine-induced seizures and mortality and that the dopamine $\mathrm{D}_{3}$ receptor is involved, at least in part, in the anticonvulsant effects of EA in mice.
\end{abstract}

\section{Introduction}

1.1. Cocaine-Induced Seizures and Death. Cocaine is a widely abused psychomotor stimulant $[1,2]$. In addition to its addiction liability, the abuse of cocaine is associated with an array of medical complications [3]. Generalized tonicclonic seizures and status epilepticus are well-documented neurologic sequelae of cocaine abuse [3,4]. Seizures may be induced by cocaine after an accidental overdose or after recreational use of relatively low doses of cocaine $[5,6]$. The incidence of seizures in cocaine users has been reported to be $2-10 \%$ [7]. High doses of cocaine have been associated with a disturbingly high number of sudden deaths in adults; a recent study documented that $3.1 \%$ of all sudden deaths in Southwest Spain were related to the use of cocaine [8].
Seizures are considered to be a major determinant of cocainerelated lethality in humans [4] and animals [9]. Sudden death in cocaine abuse may also be attributed to cardiac arrhythmia and intracerebral hemorrhage [10,11]. Currently, no specific treatment modalities offer protection against cocaine-induced seizures and death in humans.

1.2. Acupuncture. Acupuncture has been used in traditional Chinese medicine for over 2,500 years [12]. The practice has recently gained popularity and is becoming an alternative and/or complementary treatment modality for a variety of disorders worldwide [13]. In 1997, the US National Institutes of Health stated that acupuncture is a useful method for treating many conditions and has fewer side effects as 
compared with other contemporary medical treatments, such as surgery or drugs [13]. Two different strategies are used in acupuncture therapy: manual acupuncture (MA) and electroacupuncture (EA). EA is a modified form of traditional MA. The advantage of EA is in its combined therapeutic effects of transcutaneous electric nerve stimulation (TENS) and MA. Most studies use EA because the latter can be standardized by frequency, voltage, waveform, length, and so forth [14]. Studies on animals and humans have demonstrated that acupuncture results in multiple biological responses $[15$, 16]. The best characterized mechanism is via the endogenous opioid peptides and their receptors [17].

1.3. Treating Epilepsy with Acupuncture. Acupuncture has been used to treat epilepsy in China for thousands of years. Many reports have suggested that acupuncture, TENS and other alternative therapies may produce positive effects in epilepsy [19], although some studies disagree [20]. The major advantage of acupuncture is the absence of side effects. In the clinic, acupuncture at specific acupoints such as the Zusanli (ST36), Dazhui (GV14), and Baihui (GV20) has significantly ameliorated symptoms of epilepsy [21-23]. Although some evidence supports this contention [24-26], the precise mechanism remains unknown. It is noted that acupuncture to GV20 point has been used to treat loss of consciousness and tinnitus, in addition to relief of mental abstraction, sluggish speech, and hysteria [27]. Recent studies have shown that EA inhibits seizures in experimental rat models. These protective effects may be related to increased concentrations of inhibitory amino acids [28], decreased levels of nitric oxide in the central nervous system (CNS) $[26,29]$, or increased cellular glutamic acid decarboxylase67 mRNA expression, thereby increasing the production of $\gamma$-aminobutyric acid (GABA) [30]. The possibility that EA protects against cocaine-induced seizures and death has not yet been explored.

1.4. Acupuncture and Abused Drugs. Acupuncture has been widely used throughout Asian countries for treating many functional disorders, such as substance abuse and mental illness [31]. Some preclinical data have shown that acupuncture can modify the morphine withdrawal syndrome and suppress alcohol drinking behavior in rats $[32,33]$. Further evidence suggests that acupuncture at a specific acupoint (Shenmen; HT7) attenuates the ethanol-induced dopamine release in the nucleus accumbens through the $\mathrm{GABA}_{\mathrm{B}}$ receptor [34] and suppresses $c$-Fos expression in the nucleus accumbens and ventromedial striatum following a nicotine challenge in rats sensitized to nicotine [35].

1.5. c-Fos Expression. Expression of $c$-fos gene or Fos protein is widely used as a marker to identify neuronal pathways involved in the integration of noxious inputs [36-40]. High doses of cocaine have been reported to induce $c$-fos mRNA expression in many brain regions [41].

In this study, EA experiments were conducted to (1) establish the applicability of EA to cocaine-induced seizure and mortality in a mouse model, (2) determine the frequencydependent antiseizure activity of EA, and (3) correlate the efficacy of EA with the expression of Fos protein in the brain.

\section{Methods}

2.1. Laboratory Animals. Male ICR mice (28-35 g; BioLasco Taiwan Co., Ltd., Taiwan) were housed under a 12:12 h light/dark cycle with food and water available ad libitum in our animal facility for at least 4 days prior to the experiments, which were conducted between 10:00 and 17:00 h. The experimental procedures were approved by the China Medical University Institutional Animal Care and Use Committee, in accordance with the Chinese Taipei Society of Laboratory Animal Sciences guidance on care and use of laboratory animals. Experiments were designed to keep the number of mice at a minimum and care was taken to minimize suffering.

2.2. Electroacupuncture. For the EA treatment, animals were covered by paraffin film and restrained by tapes without anesthesia. A pair of stainless steel acupuncture needles (Tianjin HaingLimSou Won Medical CO., Ltd.; Gauge 40) were inserted 3-4 $\mathrm{mm}$ deep into the murine equivalent of the human GV14 and GV20, that is, (1) the skin at the location between the last cervical and the first thoracic vertebral spinous processes at the midline of the back, which is equivalent to the human GV14 and (2) at the vertex of the parietal bone, that is, the midpoint of the connecting line between the auricular apices, which is equivalent to the human GV20 acupoints $[42,43]$. EA stimuli were delivered by an EA Trio 300 stimulator (Ito, Japan) at $1 \mathrm{~mA}$ intensities for a 15 min duration at a frequency of 2,50 , or $100 \mathrm{~Hz}$, with a pulse width of $150 \mu \mathrm{s}$. The two electrodes were connected to the needles, which were inserted into GV20 and GV14. In the control group, animals were also covered by paraffin film and restrained by tape for $15 \mathrm{~min}$ [44]. A sham EA was performed by bilateral insertion of a pair of stainless steel acupuncture needles approximately 3-4 mm deep into the middle of each scapula, which is equivalent to the human Tianzong (SI11).

2.3. Behavioral Study. Following the injection of cocaine or saline, animals were placed in a plastic observation box and seizure scores were assessed by the Itzhak scale, which categorizes five stages according to their severity over a 30 min period [18]. The Itzhak stages of seizure are as follows.

Stage 1. Normal behavior (moving about the cage, sniffing, and rearing).

Stage 2. Hyperactivity (running movement characterized by rapid changes in position).

Stage 3. Animal remains in the same place for several seconds with fast repetitive movements of the head, face, mouth, or forelimb, as well as head nodding.

Stage 4. Forelimb clonus and rearing. 
Stage 5. Full motor seizures, characterized by clonus of forelimbs and hindlimbs, flexion of head or entire body, and complete loss of postural control.

2.4. Immunohistochemistry Procedure. The immunohistochemistry procedure was similar to that described by Inan et al. [45]. Two hours after the injection of saline or cocaine, animals were deeply anesthetized with urethane $(1.2 \mathrm{~g} / \mathrm{kg}$; i.p.) and perfused intracardially with ice-cold $0.1 \mathrm{M}$ phosphatebuffered saline (PBS) followed by $4 \%$ paraformaldehyde in $0.1 \mathrm{M}$ PBS. The brains were removed, postfixed for $2 \mathrm{~h}$, and kept in 30\% sucrose solution overnight. Brain sections of $50 \mu \mathrm{m}$ thickness were cut with a cryostat (LEICA CM 3050). Free-floating sections were stored in PBS at $4^{\circ} \mathrm{C}$ until immunohistochemistry was performed. Three brain sections, from $-2.255 \mathrm{~mm}$ to $-1.856 \mathrm{~mm}$ caudal to bregma, were randomly selected for immunohistochemistry procedures. Tissues were processed for c-Fos immunoreactivity by the avidin-biotin complex procedure [46]. Tissues were initially treated with $3 \% \mathrm{H}_{2} \mathrm{O}_{2}$ to reduce endogenous peroxidase activity, then washed twice for 10 min with PBS and blocked with $20 \%$ normal goat serum $(1: 20)$ for $2 \mathrm{~h}$ at room temperature. The sections were then incubated on a shaker for $2 \mathrm{~d}$ at $4^{\circ} \mathrm{C}$ with a rabbit c-Fos antibody ( $1: 1000$ dilution) (sc52; Santa Cruz, USA). After thorough rinsing, sections were incubated in biotinylated anti-rabbit immunoglobulin $\mathrm{G}$ secondary antibody (1:300 dilution; Vector Laboratories, USA) for $2 \mathrm{~h}$ at room temperature. Following two $10 \mathrm{~min}$ PBS rinses, the sections were incubated in a complex of avidin-biotinperoxidase in 1:300 solution at room temperature for $90 \mathrm{~min}$ (Vectastain ABC Elite kit, Vector Laboratories). Following three $10 \mathrm{~min}$ washes in Tris-buffered saline, the sections were placed in a $0.05 \%$ diaminobenzidine (Sigma) $/ 0.001 \% \mathrm{H}_{2} \mathrm{O}_{2}$ solution for $4-5 \mathrm{~min}$ and washed again with Tris-buffered saline 3 times for $10 \mathrm{~min}$ each. Sections were mounted on slides with $0.25 \%$ gel alcohol, air-dried, and dehydrated with graded alcohol $(50 \%, 70 \%, 95 \%$, and $100 \%$, for $6 \mathrm{~min}$ each) followed by xylene ( 3 times for $10 \mathrm{~min}$ each), and the coverslip was placed using Permount. c-Fos positive nuclei were observed under a light microscope and counted at 200x magnification. c-Fos immunoreactive nuclei were counted on the captured images using MetaMorph (Universal Imaging Corp.) software. Bilateral calculations were performed on the paraventricular thalamus, amygdala area, and caudoputamen. The number of immunoreactive nuclei was averaged for each mouse.

2.5. Drugs and Chemicals. Cocaine- $\mathrm{HCl}$ was purchased from the National Bureau of Controlled Drugs, Department of Health, Taipei, Taiwan. Freshly dissolved in $0.9 \% \mathrm{NaCl}$, all test agents were administered in a dose/volume of $10 \mathrm{mg} / \mathrm{mL}$. Cocaine at the dose of $75 \mathrm{mg} / \mathrm{kg}$ causes clonic seizures in mice [48]. Cocaine at $125 \mathrm{mg} / \mathrm{kg}$ is considered to be a lethal dose [49]. In this study, cocaine at $75 \mathrm{mg} / \mathrm{kg}$ and $125 \mathrm{mg} / \mathrm{kg}$ was injected intraperitoneally to induce seizures and death. Procaine $\mathrm{HCl}$ was purchased from Sigma Chemical Co. (St. Louis, MO, USA). Procaine ( $250 \mathrm{mg} / \mathrm{kg}$ and $400 \mathrm{mg} / \mathrm{kg}$; i.p.) was used to induce seizures and death in mice, respectively
[50]. SB-277011-A (30 mg/kg; s.c.) was purchased from Tocris Bioscience (Ellisville, MO, USA) and was used to block the dopamine $\mathrm{D}_{3}$ receptor [51].

2.6. Statistical Analysis. Data were expressed as means and the standard error of the mean (SEM). Group comparisons for seizure scores and the number of cocaine-induced c-Fos positive nuclei were evaluated by one-way ANOVA, followed by Tukey's post-hoc test. Group comparisons for mortality rates and seizure incidence were evaluated by chi-square test or Fisher's exact test. Significance was considered at $P<0.05$ for all tests. Statistical analysis was performed by SPSS version 18.0 (SPSS Inc., Chicago, IL, USA).

\section{Results}

3.1. Positioning of Acupuncture Needles. We used X-ray images to ensure accurate positioning of acupuncture needles. As shown in Figure 1(a), a mouse was anesthetized with urethane and two acupuncture needles were inserted into the GV14 and GV20 acupoints. Figure 1(b) shows the position of the acupuncture needles, as revealed by X-ray. Figure 1(c) shows the positions of GV14, GV20, and SI11 in mice.

3.2. Effects of EA on Cocaine-Induced Seizures. Firstly, the effects of EA were examined on seizures induced by a single dose of cocaine $(75 \mathrm{mg} / \mathrm{kg}$ ) in six groups of mice (a control group, three EA treatment groups, a sham EA group, and a needle insertion group). In the control group, animals were restrained with the same procedure as that used with the EA group but without EA. In the EA treatment groups, EA $(2 \mathrm{~Hz}, 50 \mathrm{~Hz}$, and $100 \mathrm{~Hz})$ was applied for $15 \mathrm{~min}$ to GV14 and GV20 acupoints prior to cocaine injection. In the sham EA group, mice received EA $(50 \mathrm{~Hz})$ applied to bilateral SI11. In the needle insertion group, needles were inserted into GV14 and GV20 acupoints, but without electrical stimulation. After undergoing control, EA, sham, or needle insertion treatment, all animals received an intraperitoneal injection of cocaine $(75 \mathrm{mg} / \mathrm{kg})$. Seizure severity was measured by the 5 -stage cocaine seizure scale published by Itzhak [18].

As shown in Figure 2, the average seizure score was significantly lower in animals treated with EA $(50 \mathrm{~Hz}) \mathrm{com}$ pared with those in the control and sham EA groups. No such effects were seen with EA $2 \mathrm{~Hz}, \mathrm{EA} 100 \mathrm{~Hz}$, or needle insertion. It appears that EA $50 \mathrm{~Hz}$ at the GV14 and GV20 acupoints significantly reduced seizure scores induced by a single cocaine administration $(75 \mathrm{mg} / \mathrm{kg})$, whereas EA at $2 \mathrm{~Hz}$ and $100 \mathrm{~Hz}$ had no such effect. Furthermore, cocaine-induced seizures were not significantly affected by either $15 \mathrm{~min}$ of needle insertion into GV14 and GV20 or by EA at SI11.

Table 1 depicts the incidence of seizures (higher or equal to stage 3 ) induced by cocaine $(75 \mathrm{mg} / \mathrm{kg}$; i.p.). Pretreatment of animals with EA $(50 \mathrm{~Hz})$ significantly reduced seizure incidence.

3.3. Effects of EA on Cocaine-Induced Death. The effects of EA on death induced by single administrations of a high dose of cocaine $(125 \mathrm{mg} / \mathrm{kg})$ were investigated in a series 


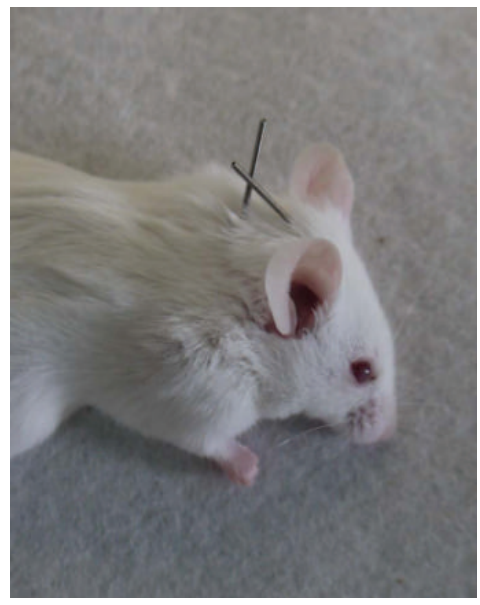

(a)

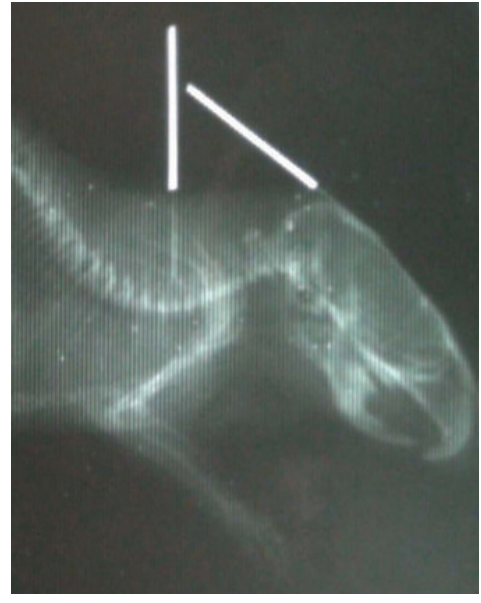

(b)

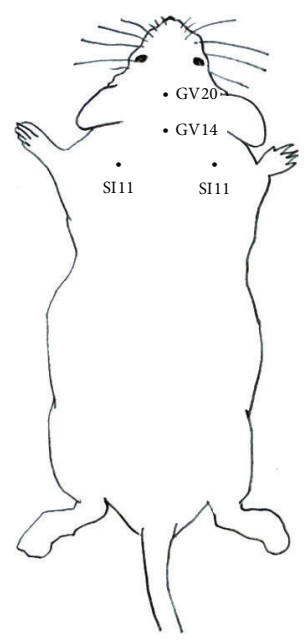

(c)

FIGURE 1: Photograph (a) and X-ray (b) of a mouse under anesthesia with acupuncture needles inserted into GV14 and GV20 acupoints. (c) Mouse schematic showing the location of the acupoints used in the study.

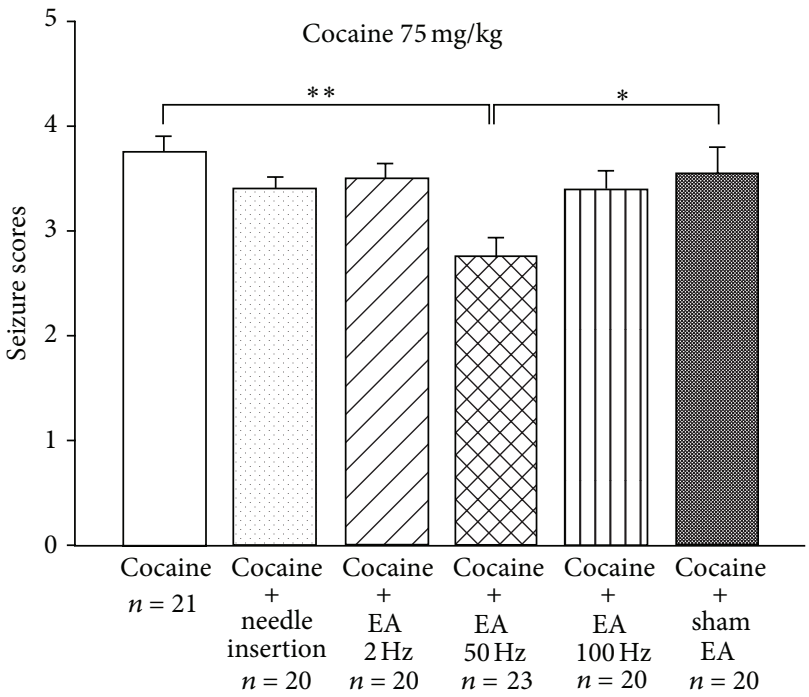

FIGURE 2: Effects of EA at different frequencies $(2 \mathrm{~Hz}, 50 \mathrm{~Hz}$, and $100 \mathrm{~Hz}$ ), needle insertion exerted at GV14 and GV20 acupoints, and sham EA $(50 \mathrm{~Hz}$; at bilateral SI11) on cocaine-induced seizures. Mice were administered with cocaine $(75 \mathrm{mg} / \mathrm{kg}$; i.p.) at $1 \mathrm{~min}$ after EA or needle insertion. Seizure severity was measured by the Itzhak fivestage scale [18]. Between-group comparisons for each group were performed by one-way ANOVA followed by Tukey's test $\left({ }^{*} P<0.05\right.$; ${ }^{* *} P<0.01 ; n$ : the number of animals).

of six groups, that is, control group, three EA treatment groups, a sham EA group, and a needle insertion group. After undergoing treatment, all animals received an intraperitoneal injection of cocaine $(125 \mathrm{mg} / \mathrm{kg})$.

As shown in Figure 3, mortality rates were significantly lower in the needle insertion and EA $(2,50 \mathrm{~Hz})$ groups as compared to mortality in the control group. The EA $(2 \mathrm{~Hz})$ group mortality rate was also lower than that of the sham EA group. Needle insertion into GV14 and GV20, as well as EA

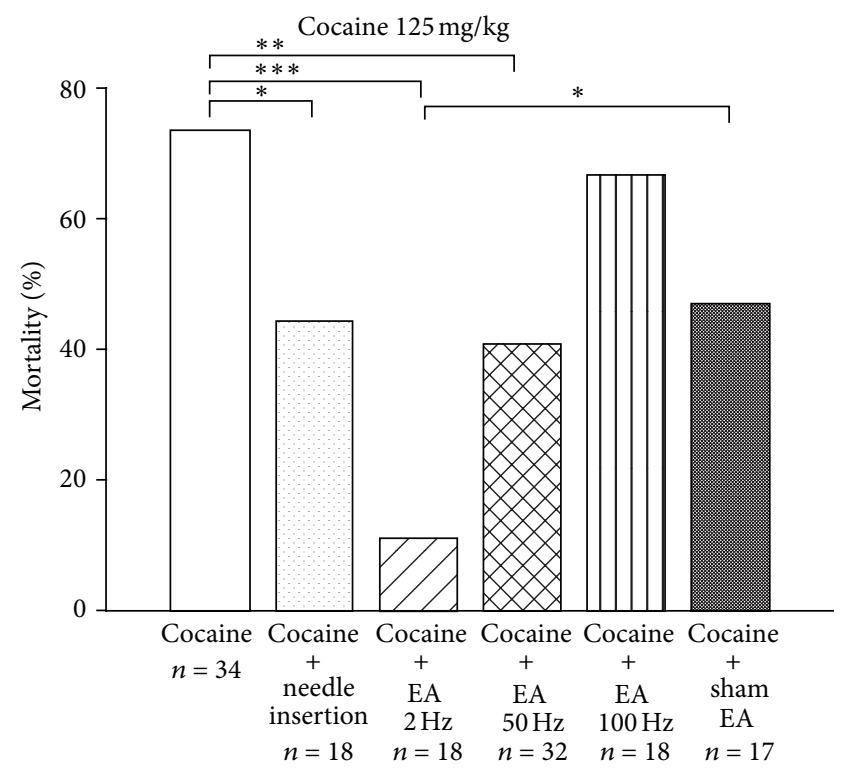

FIgURE 3: Effects of EA at different frequencies $(2 \mathrm{~Hz}, 50 \mathrm{~Hz}$, and $100 \mathrm{~Hz}$ ), needle insertion exerted at GV14 and GV20 acupoints, and sham EA (at bilateral SI11; $50 \mathrm{~Hz}$ ) on cocaine-induced mortality rates. Mice were administered with cocaine $(125 \mathrm{mg} / \mathrm{kg}$; i.p.) at $1 \mathrm{~min}$ after EA or needle insertion and mortality was monitored for 1 hour. Between-group comparisons for each group were performed by chisquare test $\left({ }^{*} P<0.05 ;{ }^{* *} P<0.01 ;{ }^{* * *} P<0.001 ; n\right.$ : the number of animals).

at $2 \mathrm{~Hz}$ and $50 \mathrm{~Hz}$ applied to GV14 and GV20, significantly reduced the mortality rate induced by a single dose of cocaine $(125 \mathrm{mg} / \mathrm{kg})$. However, EA at $100 \mathrm{~Hz}$ had no such effect. EA at SI11 as a sham control reduced the mortality rate induced by cocaine but did not reach a statistically significant level.

3.4. Effects of EA on Procaine-Induced Seizure and Death. In addition to inhibiting dopamine uptake, cocaine acts as 


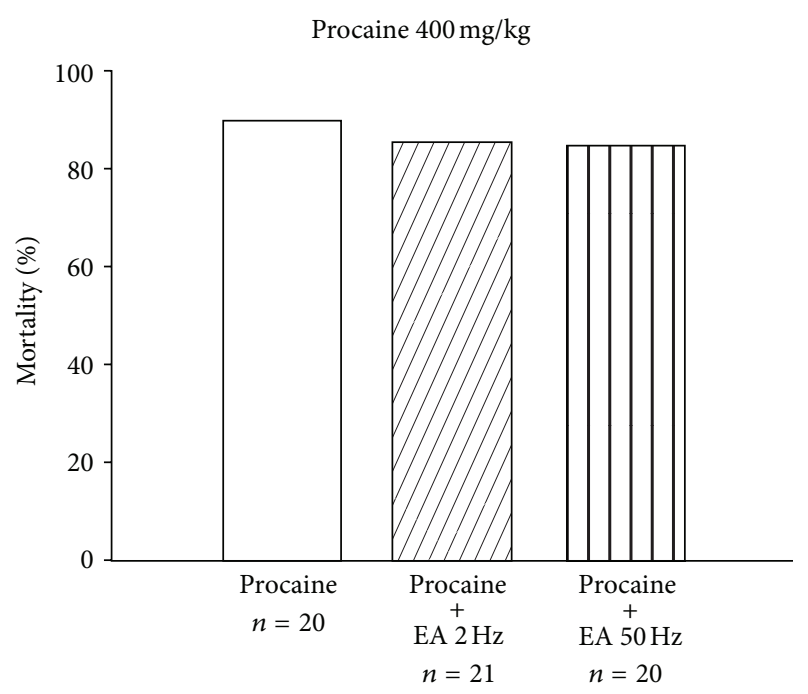

Figure 4: Effects of EA at $2 \mathrm{~Hz}$ and $50 \mathrm{~Hz}$ exerted at GV14 and GV20 acupoints on procaine-induced $(400 \mathrm{mg} / \mathrm{kg}$, i.p) mortality rates. At $1 \mathrm{~min}$ after EA, procaine was injected and the mortality was monitored for 1 hour. Between-group comparisons for each group were performed by chi-square test or Fisher's exact test. No significant between-group differences were observed ( $n$ : the number of animals).

TABle 1: EA $(50 \mathrm{~Hz})$ applied to GV14 and GV20 reduced the incidence of cocaine-induced seizures but did not alter the incidence of procaine-induced seizures.

\begin{tabular}{lcc}
\hline & Control & EA 50 Hz \\
\hline Cocaine (75 mg/kg; i.p.) & $20 / 21$ & $14 / 21^{*}$ \\
Procaine (250 mg/kg; i.p.) & $8 / 9$ & $8 / 9$ \\
\hline
\end{tabular}

The proportion of mice exhibiting seizures is shown here. The effects of cocaine, alone and in combination with EA, were compared by Fisher's exact test $\left({ }^{*} P<0.05\right)$. Similarly, the effects of procaine, alone and in combination with EA, were compared.

a local anesthetic by blocking voltage-dependent $\mathrm{Na}^{+}$channels $[52,53]$. Local anesthetics, such as procaine, can cause $\mathrm{CNS}$ and cardiovascular toxicity when plasma concentrations are increased by accidental intravenous injection of a lethal dose of procaine [54]. However, procaine has no CNS stimulant effects compared with those of cocaine. Therefore, the effects of EA on procaine-induced seizures and death were examined.

The seizure incidence of procaine-treated mice $(250 \mathrm{mg} /$ $\mathrm{kg}$; i.p.) is shown in Table 1 . When animals were pretreated with EA $(50 \mathrm{~Hz})$ at acupoints GV14 and GV20, the incidence was not affected. Furthermore, as shown in Figure 4, mortality rates did not differ significantly between the control group and $\mathrm{EA}(2$ and $50 \mathrm{~Hz}$ ) groups. It appears that EA at $2 \mathrm{~Hz}$ and $50 \mathrm{~Hz}$, when applied to GV14 and GV20, fails to affect the mortality rate associated with procaine $(400 \mathrm{mg} / \mathrm{kg}$; i.p.) in mice.

3.5. EA Attenuation of Cocaine-Induced c-Fos Expression. This series of studies was undertaken to test the effects of

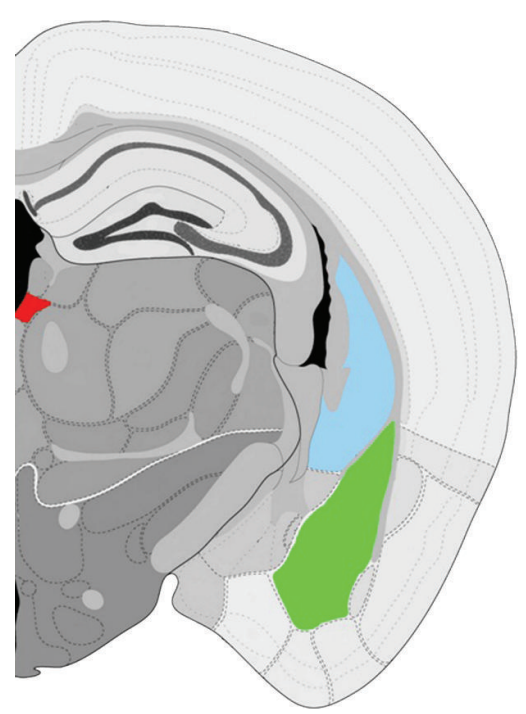

FIGURE 5: Schematic representation of the brain regions in which the c-Fos immunoreactive neurons were counted. The paraventricular thalamus (in red), the caudoputamen (blue), and the amygdala area (including lateral amygdalar nucleus, basolateral amygdalar nucleus, and basomedial amygdalar nucleus; green) are indicated. The drawing has been modified from the Allen Brain Atlas online database (http://www.brain-map.org/; [47]).

EA on cocaine-induced $(75 \mathrm{mg} / \mathrm{kg}) \mathrm{c}$-Fos expression in the mouse brain. Mice were divided into 4 groups: saline control, EA alone, cocaine, and cocaine plus EA.

All mice in the saline control group and cocaine group were restrained without EA. Mice in the EA alone and cocaine plus EA groups received EA $(50 \mathrm{~Hz})$ at GV14 and GV20 acupoints. Following the restraining procedure or EA, the mice were allowed to recover for $1 \mathrm{~min}$, before being injected with saline (saline control and EA-alone groups) or cocaine (cocaine group and cocaine plus EA groups).

Figure 5 shows the brain regions in which the c-Fos immunoreactive neurons were counted. Results are shown in Figures 6, 7, and 8. c-Fos expression was examined in the three brain areas, including paraventricular thalamus (Figure 6), amygdala area (Figure 7), and caudoputamen (Figure 8). Few c-Fos positive nuclei were found in these areas in the saline control group. In the EA-alone group, c-Fos positive nuclei were found only in the paraventricular thalamus (Figure 6). It appears that EA $50 \mathrm{~Hz}$ alone had no significant effect on c-Fos expression, except in the paraventricular thalamus. In the cocaine group, c-Fos positive nuclei were found in all three areas and at significantly higher levels than those seen in the saline control group. In the cocaine plus EA group, although c-Fos positive nuclei were noted in all three brain areas, c-Fos-positive nuclei were significantly decreased in the paraventricular thalamus (Figure 6) as compared to those in the cocaine group. It appears that pretreatment with EA $50 \mathrm{~Hz}$ significantly reduced the number of c-Fos positive cells induced by cocaine in the paraventricular thalamus, but not in the amygdala area (Figure 7) and caudoputamen (Figure 8). 


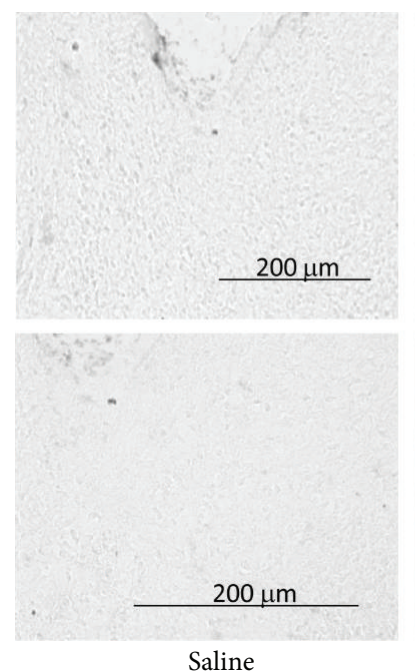

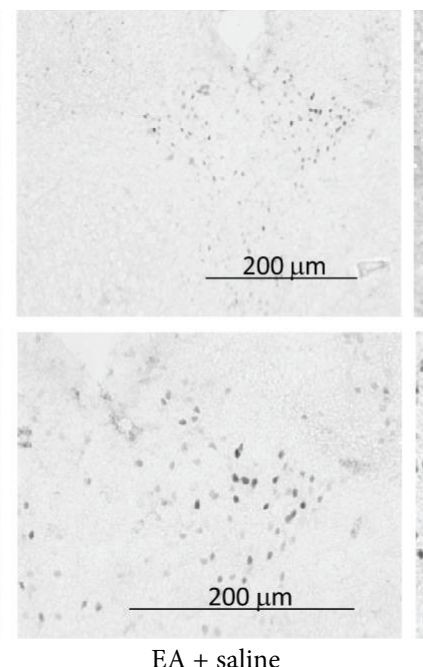

$\mathrm{EA}+$ saline

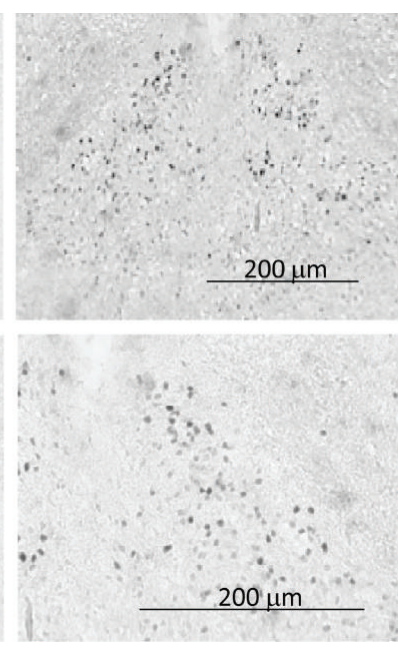

Cocaine

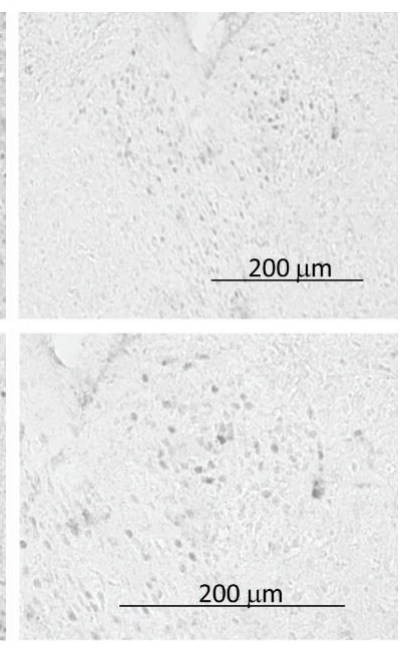

$\mathrm{EA}+$ cocaine

(a)

Paraventricular thalamus

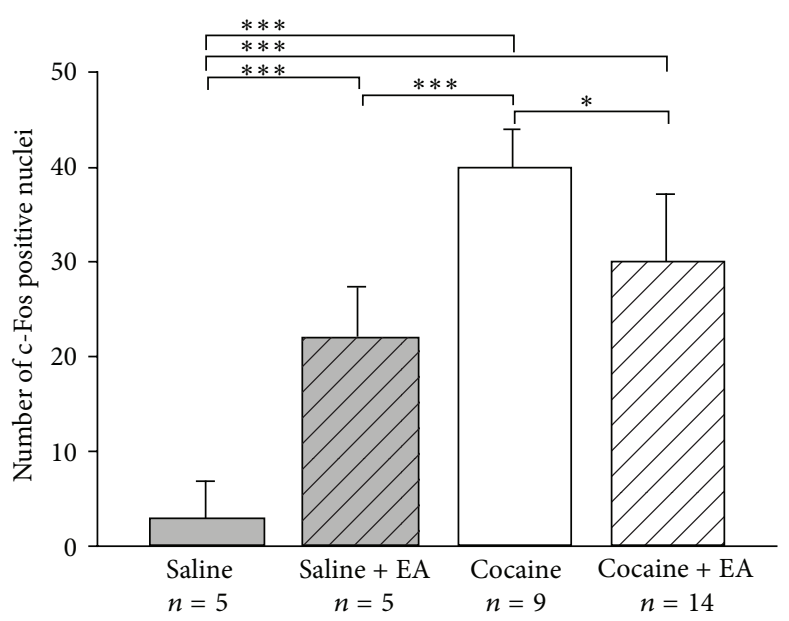

(b)

Figure 6: (a) Representative photomicrographs of c-Fos expression induced by cocaine in the paraventricular thalamus and the effects of EA. c-Fos expression was not observed among saline controls, whereas c-Fos expression was evident in the paraventricular thalamus among animals in the EA-alone, cocaine-alone (75 mg/kg; i.p.), and cocaine plus EA groups. (b) Effects of EA on controls and cocaine-induced c-Fos expression in the paraventricular thalamus. The numbers of c-Fos positive nuclei were counted and averaged from three randomly chosen sections from each animal in each group. EA at $50 \mathrm{~Hz}$ was applied to the GV14 and GV20 acupoints. EA increased c-Fos expression in the paraventricular thalamus, while EA decreased the number of c-Fos positive nuclei induced by cocaine. Between-group comparisons for each group were performed by ANOVA, followed by Tukey's test $\left({ }^{*} P<0.05 ;{ }^{* * *} P<0.001\right.$; $n$ : the number of animals).

3.6. EA Effects on Cocaine-Induced Seizures Blocked by the Dopamine $\mathrm{D}_{3}$ Receptor Antagonist SB-277011-A. Cocaine enhances monoamine system activity through the blockade of dopamine and serotonin reuptake. However, the mechanism of seizures induced by cocaine is complex and involves interaction of the drug with several neurotransmitter systems as well as with voltage-dependent sodium channels [55]. It is believed that dopamine receptors play an important role in cocaine-induced seizures and death. It is known that the paraventricular thalamus expresses dopamine $\mathrm{D}_{3}$ mRNA
[56] and we found that EA induced c-Fos expression in the paraventricular thalamus. We therefore tested the possibility that dopamine $\mathrm{D}_{3}$ receptors may mediate the effects of EA on cocaine-induced seizures.

Four groups were included: a control group, an SB277011-A group, an EA group, and an SB-277011-A plus EA group. In the SB-277011-A group and EA group plus SB277011-A, the compound SB-277011-A (30 mg/kg) was administered subcutaneously for $30 \mathrm{~min}$ prior to the restraining procedure or EA treatment. After the restraining procedure 

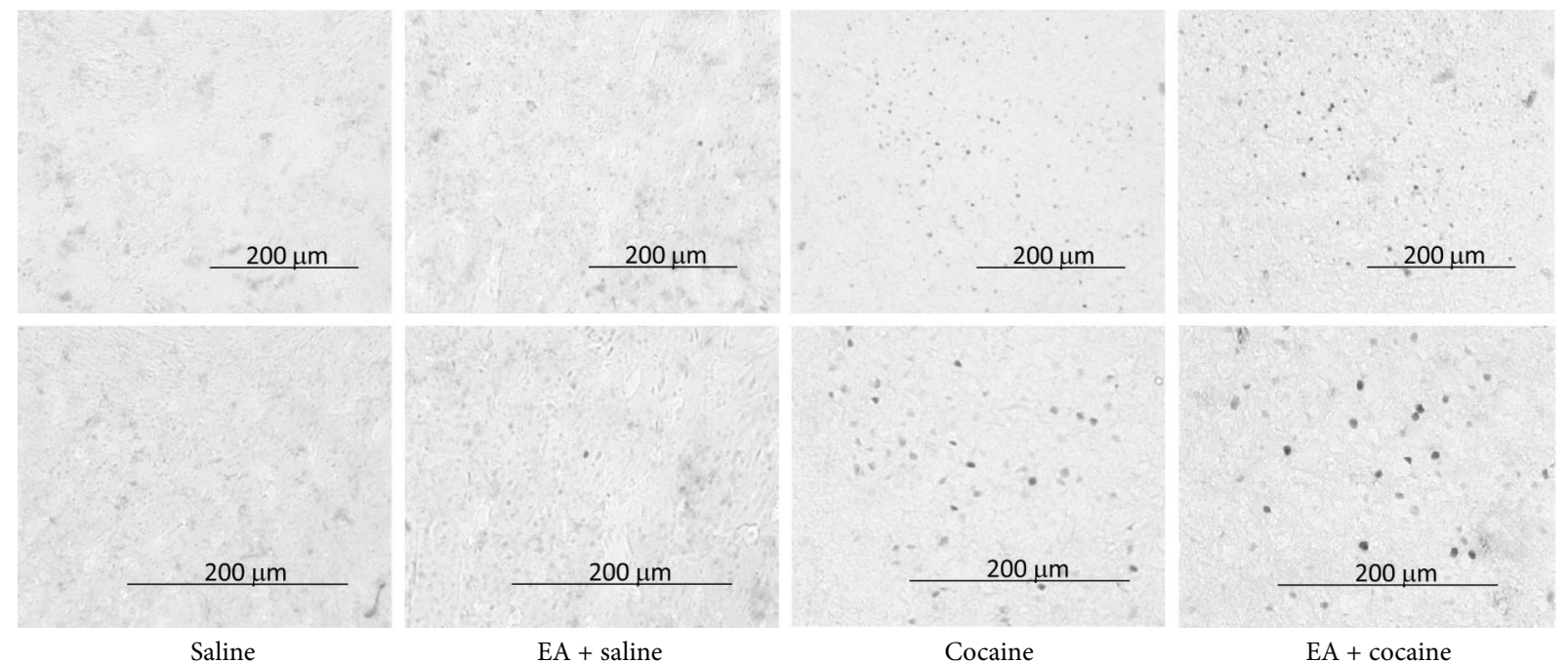

(a)

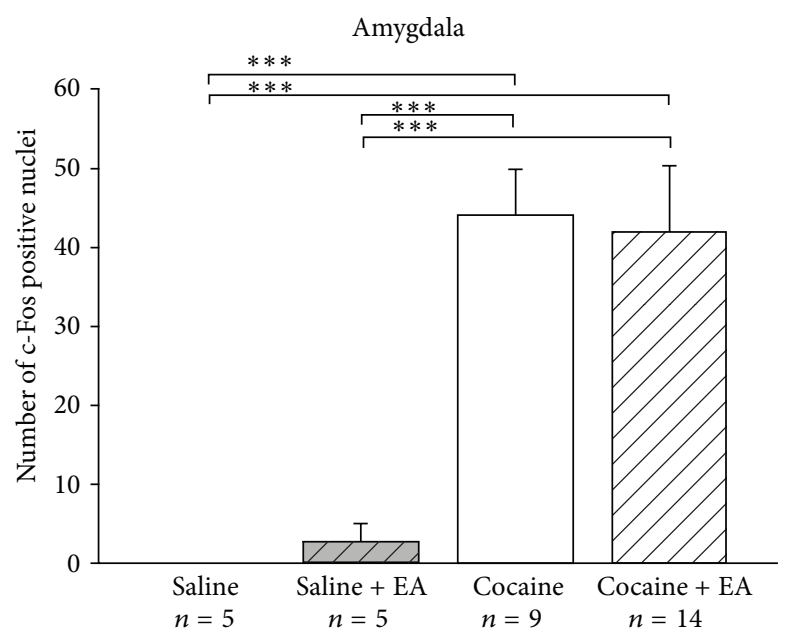

(b)

FIGURE 7: (a) Representative photomicrographs of c-Fos expression induced by cocaine in the amygdala and the effects of EA. Whereas c-Fos expression was absent among animals in the saline control and EA plus saline groups, c-Fos expression in the amygdala was observed in animals treated with cocaine ( $75 \mathrm{mg} / \mathrm{kg}$; i.p.) and cocaine plus EA. (b) Effects of EA on controls and cocaine-induced c-Fos expression in the amygdala. The numbers of c-Fos positive nuclei were counted and averaged from three randomly chosen sections from each animal in each group. EA at $50 \mathrm{~Hz}$ was applied to the GV14 and GV20 acupoints. Cocaine administration induced a marked level of c-Fos expression, while EA did not significantly decrease the number of c-Fos positive nuclei induced by cocaine. Between-group comparisons for each group were performed by ANOVA, followed by Tukey's test $\left({ }^{* * *} P<0.001 ; n\right.$ : the number of animals).

or EA treatment, all animals received an intraperitoneal injection of cocaine $(75 \mathrm{mg} / \mathrm{kg})$. Seizure severity was measured by the Itzhak five-stage cocaine seizure scale [18].

As shown in Figure 9, the EA $(50 \mathrm{~Hz})$ group had significantly lower average seizure scores compared with those of the remaining three groups. Notably, seizure scores in the SB277011-A group and SB-277011-A plus EA group did not differ significantly from the control group but were significantly higher than those in the EA group. It appears that while the dopamine $\mathrm{D}_{3}$ receptor antagonist, SB-277011-A $(30 \mathrm{mg} / \mathrm{kg}$; s.c.), did not affect cocaine-induced seizure severity, it did prevent the effects of EA on cocaine-induced seizures.

\section{Discussion}

4.1. EA Decreases Cocaine-Induced Effects. The psychostimulant and euphoric effects of cocaine are considered to be associated with the blockade of dopamine uptake in the CNS. Acupuncture has been widely used throughout Asian countries for treating various functional disorders, including substance abuse [31]. Immunohistochemical investigations by Lee et al. (2009) [57] reported that acupuncture can reduce repeated cocaine-induced locomotor activity in rats and the expression of tyrosine hydroxylase $(\mathrm{TH})$ in the rat brain, which suggests that acupuncture may effectively inhibit 

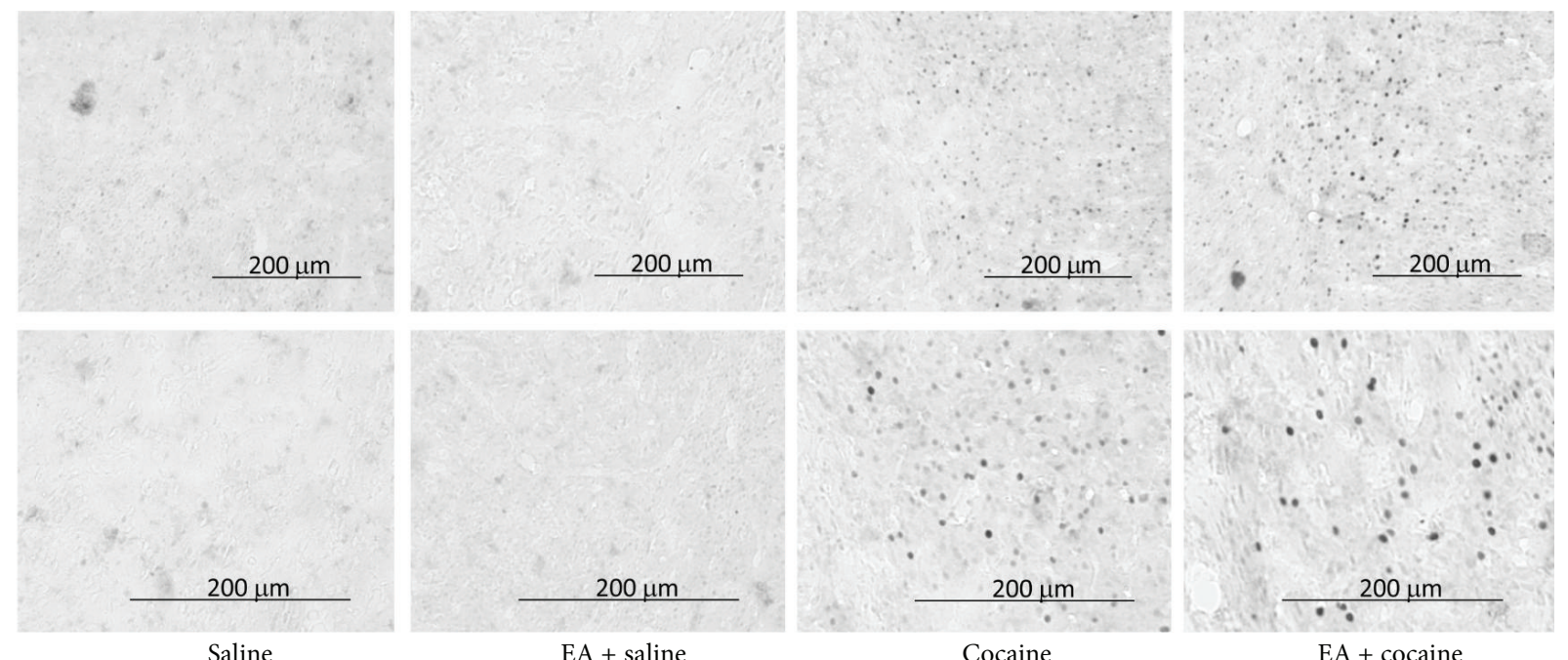

$\mathrm{EA}+$ saline

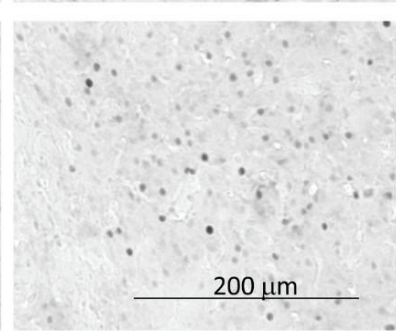

Cocaine
$\mathrm{EA}+$ cocaine

(a)

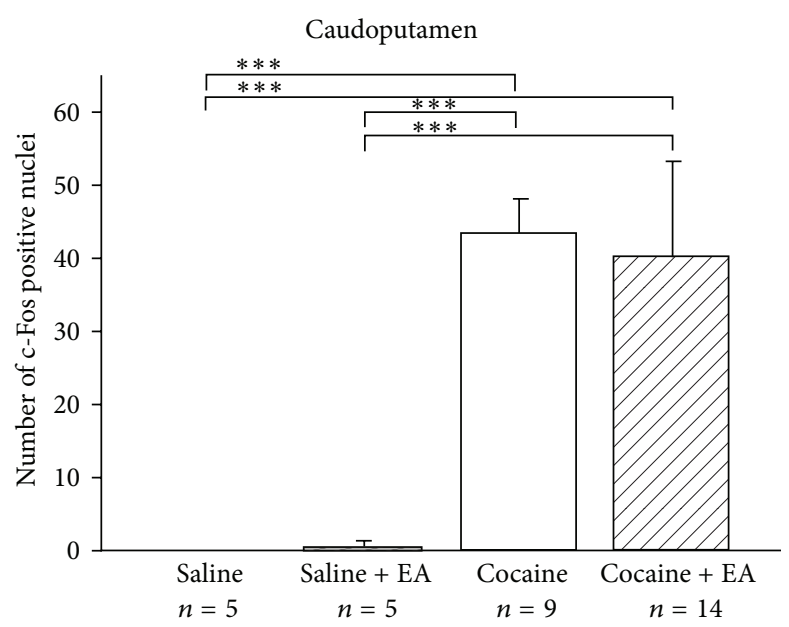

(b)

FIGURE 8: (a) Representative photomicrographs of c-Fos expression induced by cocaine in the caudoputamen and the effects of EA. Whereas c-Fos expression was not observed in the saline control and EA plus saline groups, c-Fos expression in the caudoputamen was observed among animals treated with cocaine ( $75 \mathrm{mg} / \mathrm{kg}$; i.p.), and cocaine plus EA. (b) Effects of EA on controls and cocaine-induced c-Fos expression in the caudoputamen. The numbers of c-Fos positive nuclei were counted and averaged from three randomly chosen sections from each animal in each group. EA at $50 \mathrm{~Hz}$ was applied to the GV14 and GV20 acupoints. Cocaine administration induced a marked level of c-Fos expression, while EA did not significantly decrease the number of c-Fos positive nuclei induced by cocaine. Between-group comparisons for each group were performed by ANOVA, followed by Tukey's test $\left({ }^{* * *} P<0.001 ; n\right.$ : the number of animals).

the behavioral effects of cocaine by modulating the central dopaminergic system.

As mentioned earlier, cocaine abuse is associated with a risk of various medical complications, including seizures and death [3]. It has previously been reported that cocaine at doses ranging from $2.5 \mathrm{mg} / \mathrm{kg}$ to $20 \mathrm{mg} / \mathrm{kg}$ (i.p.) causes conditioned place preference, representing the rewarding effects of cocaine [58]. At a dose as high as $40 \mathrm{mg} / \mathrm{kg}$ (i.p.), cocaine caused seizures in mice [59]. The calculated $\mathrm{ED}_{50}$ value for cocaine-induced seizures is $58.84 \mathrm{mg} / \mathrm{kg}$ [59]. Cocaine at $75 \mathrm{mg} / \mathrm{kg}$ (i.p.) produces seizures in more than $90 \%$ of mice [48]. Cocaine at $125 \mathrm{mg} / \mathrm{kg}$ is considered to be a lethal dose [49]. In the present study, we found that EA at $50 \mathrm{~Hz}$ exerted at GV14 and GV20 acupoints significantly reduced the seizure severity induced by a single cocaine (75 mg/kg; i.p.) administration. Moreover, needle insertion into GV14 and GV20 as well as EA at $2 \mathrm{~Hz}$ and $50 \mathrm{~Hz}$ exerted at GV14 and GV20 acupoints significantly reduced the mortality rate induced by a single cocaine $(125 \mathrm{mg} / \mathrm{kg})$ administration. Conversely, EA at $50 \mathrm{~Hz}$ applied to bilateral SIll acupoints had no such effects. In addition, EA failed to protect against procaine-induced seizure incidence and lethality in mice. We report here for the first time that EA reduced seizures and mortality induced by a high dose of cocaine.

4.2. Cocaine-Induced c-Fos Expression and Effects of EA. Expression of the $c$-fos gene or Fos protein is commonly 


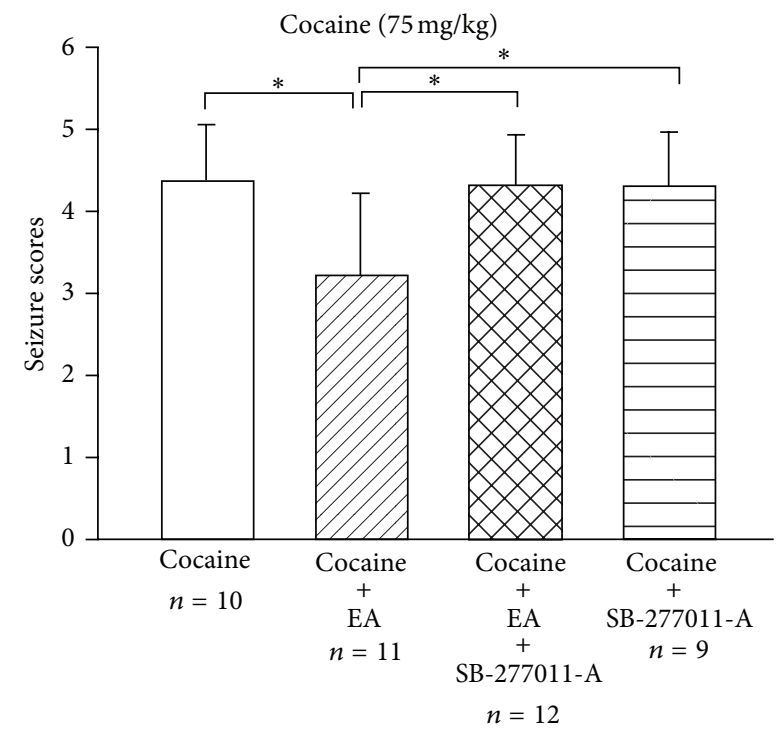

FIgURE 9: Effects of the dopamine $\mathrm{D}_{3}$ receptor antagonist, SB-277011-A, on the anticonvulsant effects of EA. SB-277011-A $(30 \mathrm{mg} / \mathrm{kg}$ ) was administered subcutaneously $30 \mathrm{~min}$ prior to the control restraining procedure or EA treatment. EA $(50 \mathrm{~Hz})$ was applied for 15 min to the GV14 and GV20 acupoints prior to cocaine injection. After the restraining procedure or EA treatment, all animals received an intraperitoneal injection of cocaine $(75 \mathrm{mg} / \mathrm{kg})$. Seizure severity was measured by the Itzhak five-stage scale [18]. Between-group comparisons for each group were performed by oneway ANOVA, followed by Tukey's test $\left({ }^{*} P<0.05 ; n\right.$ : the number of animals).

used as a marker for neuronal activation, seizure pathways, and sites of action of neuroactive drugs [60-64]. It has been reported that an acute injection of cocaine $(65 \mathrm{mg} / \mathrm{kg})$ in rats increased expression of $c$-fos mRNA in the dentate gyrus of the hippocampus and olfactory bulb and limbic cortical regions as well as the striatum and ventromedial hypothalamic nucleus [41].

In this study, we focused on three brain areas: the paraventricular thalamus, amygdala, and caudoputamen. We found that cocaine at a dose of $75 \mathrm{mg} / \mathrm{kg}$ (i.p.) induced marked c-Fos expression in all areas. Pretreatment with $50 \mathrm{~Hz}$ EA significantly reduced the number of c-Fos positive cells induced by cocaine in the paraventricular thalamus, but not in the amygdala or caudoputamen.

The thalamus is considered to be an important interface between the ventral pallidum and the dorsal medial prefrontal cortex which may therefore contribute to the development of compulsive drug-seeking behavior [65]. One thalamic nucleus that is of particular interest is the paraventricular thalamus, a component of the dorsal midline thalamic group [66]. The thalamic paraventricular nucleus projects to the nucleus accumbens and other limbic sites, including the prefrontal cortex, amygdala, and hippocampus; these projections are predominantly glutamatergic [67]. The paraventricular thalamus also receives a dopaminergic innervation, in part derived from the ventral tegmental area, and paraventricular thalamus neurons expressing dopamine $\mathrm{D}_{3}$ mRNA [56]. The paraventricular thalamus has been implicated in stress reactivity [68], reward-seeking behavior [69], and general arousal activity [70]. Furthermore, inactivation of the paraventricular thalamus prevents context-induced reinstatement of alcoholseeking [71] and cocaine-primed reinstatement in rats [72]. Paraventricular thalamus lesions block cocaine sensitization [67].

The paraventricular thalamus is related to seizures activity. Mraovitch and Calando [73] used immunocytochemistry to determine the regional and temporal distribution of Fos protein expression in awake and unrestrained rats after a unilateral stereotaxic microinjection of the cholinergic agonist carbachol in the thalamic ventroposterolateral and reticular nuclei, previously shown to cause limbic and generalized seizures [73]. They found that paraventricular thalamus activation occurred after $15 \mathrm{~min}$ after administration of epileptic agents.

The amygdala is involved in both temporal lobe epilepsy and in cocaine mechanisms in the brain. In particular, the central nucleus of the amygdala is a highly epileptogenic brain area and, of the amygdaloid nuclei, responds most rapidly to a kindling stimulus [74]. The caudoputamen is a part of the striatum area and plays an important role in control of movement in animals [75-77].

As shown by our results and the published literature [41], acute cocaine administration increases c-Fos expression in many brain areas. Among these areas, the paraventricular thalamus and amygdala are structures associated with seizures, while the caudoputamen is associated with movement control. We therefore analyzed c-Fos expression in these three specific regions. Our results implicate involvement of the paraventricular thalamus in the effects of EA on cocaineinduced seizures.

4.3. EA Induces c-Fos Expression in the Paraventricular Thalamus and Dopamine $D_{3}$ Receptors Are Involved in the Effects of EA. Medeiros et al. (2003) reported higher levels of cFos expression induced by EA at the ST36 point in animals, that is, in the dorsal raphe nucleus, locus coeruleus, posterior hypothalamus, and central medial nucleus of the thalamus [78]. In the present study, we found that EA alone at GV14 and GV20 acupoints induced significant c-Fos expression in the paraventricular thalamus.

Recent research indicates that dopamine $\mathrm{D}_{3}$ receptors may play an important role in cocaine-induced seizures [51]. The $\mathrm{D}_{3}$ antagonist SB-277011-A has been used to block dopamine $\mathrm{D}_{3}$ receptors, at doses ranging from $3 \mathrm{mg} / \mathrm{kg}$ to $30 \mathrm{mg} / \mathrm{kg}$ (s.c.) [18, 79]. SB-277011-A prevented the anticonvulsant effects of the $\mathrm{D}_{3} / \mathrm{D}_{2}$ receptor agonist (+)-PD-128,907 on cocaine-induced seizures. Notably, the protection afforded by $(+)-P D-128,907$ was eliminated in $\mathrm{D}_{3}$ receptor-deficient mice, whereas the anticonvulsant effects of $(+)-P D-128,907$ were preserved in $\mathrm{D}_{2}$ receptor knockout mice.

As mentioned above, the paraventricular thalamus expresses dopamine $\mathrm{D}_{3}$ mRNA, while EA alone induces cFos expression in the paraventricular thalamus. We therefore sought to determine whether dopamine $\mathrm{D}_{3}$ receptors mediate the effects of EA on cocaine-induced seizures. Our results 
revealed that while the $\mathrm{D}_{3}$ receptor antagonist SB-277011-A did not affect cocaine-induced seizure severity, it prevented the effects of EA on cocaine-induced seizures. This finding suggests that the $\mathrm{D}_{3}$ receptor is involved, at least in part, in the anticonvulsant effects of EA.

Interesting topics that remain for future studies include an investigation into whether intraparaventricular thalamus injection of $\mathrm{a}_{3}$ receptor antagonist prevents EA-induced anticonvulsive effects and whether a $\mathrm{D}_{3}$ receptor antagonist antagonizes EA-induced changes to c-Fos expression in the paraventricular thalamus or has any effect on cocaineinduced mortality.

\subsection{A Complex Mechanism Underlies Cocaine-Induced Death.} It is noted that EA at $50 \mathrm{~Hz}$ only, when exerted at GV14 and GV20 acupoints, significantly reduced seizure severity induced by a single cocaine ( $75 \mathrm{mg} / \mathrm{kg}$; i.p.) administration. However, needle insertion into GV14 and GV20 acupoints as well as EA at $2 \mathrm{~Hz}$ and $50 \mathrm{~Hz}$ effectively reduced the mortality rate induced by a single cocaine $(125 \mathrm{mg} / \mathrm{kg})$ administration. As mentioned earlier, seizures are considered to be a major determinant of cocaine-related lethality in both humans [4] and animals [9]. However, the mechanism of sudden death in cocaine abuse also includes cardiac arrhythmia and intracerebral hemorrhage $[10,11]$. Cocaine produces euphoria, elation, mood elevation, alertness, attention focusing, and fatigue reduction through interactions with monoamine transporters [80]. In addition to the central effects, cocaine also blocks norepinephrine uptake and increases sympathetic activity in the periphery [81]. Overstimulation of sympathetic activity may cause cardiac arrhythmia and intracerebral hemorrhage and hence may contribute to cocaine-induced fatality $[10,11]$. EA frequency-specific differences observed in protection against seizures and death may be because the mechanism that induces death is more complicated than that involved in seizures. It is recognized that acupuncture can account for different effects in the autonomic nervous system $[82,83]$. For example, the GV14 acupoint is capable of increasing parasympathetic activities while simultaneously suppressing sympathetic activities [82]. This may explain why $\mathrm{EA}$ at $2 \mathrm{~Hz}$ is particularly effective against cocaine-induced death.

4.5. EA Frequency. The best-known mechanism of EA is via the endogenous opiates and their receptors. Different kinds of endogenous opioid peptides, such as $\beta$-endorphin, enkephalin, endomorphin, and dynorphin, reportedly act in a frequency-dependent manner in EA. At a low frequency $(2 \mathrm{~Hz})$, EA accelerated the release of $\beta$-endorphin and enkephalin in the CNS, whereas high-frequency EA $(100 \mathrm{~Hz})$ accelerated the release of dynorphin [17, 84-86]. In the present study, we found that EA applied to GV14 and GV20 acupoints at the frequency of $50 \mathrm{~Hz}$ is most effective in reducing seizure severity induced by a single cocaine administration. There were few reports in the literature as to the effects of EA $50 \mathrm{~Hz}$ as compared to those of EA 2 and $100 \mathrm{~Hz}$. However, it has been recently reported that EA $60 \mathrm{~Hz}$ increases the pain threshold by a greater extent than any other frequency [87]. EA at a frequency of $60 \mathrm{~Hz}$ induced the simultaneous release of met-enkephalin, $\beta$-endorphin, and dynorphin-A in extensive analgesia-related nuclei and areas of the CNS, such as the periaqueductal gray, the paraventricular nucleus of the hypothalamus, the ventromedial nucleus of the hypothalamus, the dorsal raphe nucleus, and the nucleus raphe magnus, amongst others. These results suggest that EA at $60 \mathrm{~Hz}$ may contribute to optimal analgesic effects. The effects of EA at 50 or $60 \mathrm{~Hz}$ deserve to be studied further [87].

No effective treatment currently exists for cocaine-induced seizures and death. Our results suggest that EA reduces seizure severity and death caused by cocaine in an animal model of cocaine abuse. We found evidence for involvement of the dopamine $\mathrm{D}_{3}$ receptor, at least in part, in the anticonvulsant effects of EA.

\section{Acknowledgments}

The authors are grateful to Ms. Iona MacDonald and Ms. YaTing Wu for their help in producing the final paper. This work was supported by Grants NSC 100-2320-B-039-018- and NSC 101-2320-B-039-035-MY3 from the National Science Council, Taipei, Taiwan.

\section{References}

[1] C. Haasen, M. Prinzleve, H. Zurhold et al., "Cocaine use in Europe-a multi-centre study: methodology and prevalence estimates," European Addiction Research, vol. 10, no. 4, pp. 139146, 2004.

[2] R. A. Lange and L. D. Hillis, "Sudden death in cocaine abusers," European Heart Journal, vol. 31, no. 3, pp. 271-273, 2010.

[3] N. L. Benowitz, "Clinical pharmacology and toxicology of cocaine," Pharmacology and Toxicology, vol. 72, no. 1, pp. 3-12, 1993.

[4] W. H. Spivey and B. Euerle, "Neurologic complications of cocaine abuse," Annals of Emergency Medicine, vol. 19, no. 12, pp. 1422-1428, 1990.

[5] A. K. Dhuna, A. Pascual-Leone, F. Langendorf, and D. C. Anderson, "Epileptogenic properties of cocaine in humans," NeuroToxicology, vol. 12, no. 3, pp. 621-626, 1991.

[6] L. D. Kramer, G. E. Locke, A. Ogunyemi, and L. Nelson, "Cocaine-related seizures in adults," The American Journal of Drug and Alcohol Abuse, vol. 16, no. 3-4, pp. 309-317, 1990.

[7] A. Pascual-Leone, A. Dhuna, I. Altafullah, and D. C. Anderson, "Cocaine-induced seizures," Neurology, vol. 40, no. 3, part 1, pp. 404-407, 1990.

[8] J. Lucena, M. Blanco, C. Jurado et al., "Cocaine-related sudden death: a prospective investigation in South-West Spain," European Heart Journal, vol. 31, no. 3, pp. 318-329, 2010.

[9] J. D. Catravas and I. W. Water, "Acute cocaine intoxication in the conscious dog: studies on the mechanism of lethality," Journal of Pharmacology and Experimental Therapeutics, vol. 217, no. 2, pp. 350-356, 1981.

[10] E. Secemsky, D. Lange, D. D. Waters, N. F. Goldschlager, and P. Y. Hsue, "Hemodynamic and arrhythmogenic effects of cocaine in hypertensive individuals," Journal of Clinical Hypertension, vol. 13, no. 10, pp. 744-749, 2011.

[11] S. Toossi, C. P. Hess, N. K. Hills, and S. A. Josephson, "Neurovascular complications of cocaine use at a tertiary stroke center," 
Journal of Stroke and Cerebrovascular Diseases, vol. 19, no. 4, pp. 273-278, 2010.

[12] J. N. Wu, "A short history of acupuncture," Journal of Alternative and Complementary Medicine, vol. 2, no. 1, pp. 19-21, 1996.

[13] NIH, "NIH consensus conference. Acupuncture," The Journal of the American Medical Association, vol. 280, no. 17, pp. 1518-1524, 1998.

[14] J. G. Lin and W. L. Chen, "Acupuncture analgesia: a review of its mechanisms of actions," The American Journal of Chinese Medicine, vol. 36, no. 4, pp. 635-645, 2008.

[15] J. H. Liu, J. Yan, S. X. Yi, X. R. Chang, Y. P. Lin, and J. $\mathrm{M}$. $\mathrm{Hu}$, "Effects of electroacupuncture on gastric myoelectric activity and substance $\mathrm{P}$ in the dorsal vagal complex of rats," Neuroscience Letters, vol. 356, no. 2, pp. 99-102, 2004.

[16] H. R. Middlekauff, J. B. Shah, J. L. Yu, and K. Hui, "Acupuncture effects on autonomic responses to cold pressor and handgrip exercise in healthy humans," Clinical Autonomic Research, vol. 14, no. 2, pp. 113-118, 2004.

[17] J. S. Han, "Acupuncture: neuropeptide release produced by electrical stimulation of different frequencies," Trends in Neurosciences, vol. 26, no. 1, pp. 17-22, 2003.

[18] Y. Itzhak, "Attenuation of cocaine kindling by 7-nitroindazole, an inhibitor of brain nitric oxide synthase," Neuropharmacology, vol. 35, no. 8, pp. 1065-1073, 1996.

[19] K. J. Yin, X. H. Chen, R. H. Wang, Z. Q. Lei, and Y. W. Gao, "Effect and mechanisms of anti-epilepsy effect by magentacupuncture," Chinese Acupuncture and Moxibustion, vol. 10, pp. 620-625, 1999.

[20] R. Kloster, P. G. Larsson, R. Lossius et al., "The effect of acupuncture in chronic intractable epilepsy," Seizure, vol. 8, no. 3, pp. 170-174, 1999.

[21] J. L. Zhang, S. P. Zhang, and H. Q. Zhang, "Antiepileptic effect of electroacupuncture versus vagus nerve stimulation in the rat thalamus," Neuroscience Letters, vol. 441, no. 2, pp. 183-187, 2008.

[22] Y. S. Peng, "Clinical study on treatment of infantile primary epilepsy with acupoint catgut-implantation therapy," World Journal of Acupuncture-Moxibustion, vol. 13, no. 1, pp. 38-41, 2003.

[23] Y. Ren, "Acupuncture treatment of Jacksonian epilepsy-a report of 98 cases," Journal of Traditional Chinese Medicine, vol. 26, no. 3, pp. 177-178, 2006.

[24] D. M. Chao, G. Chen, and J. S. Cheng, "Melatonin might be one possible medium of electroacupuncture anti-seizures," Acupuncture and Electro-Therapeutics Research, vol. 26, no. 1-2, pp. 39-48, 2001.

[25] J. G. Dos Santos, A. Tabosa, F. H. M. do Monte, M. M. Blanco, A. de Oliveira Freire, and L. E. Mello, "Electroacupuncture prevents cognitive deficits in pilocarpine-epileptic rats," Neuroscience Letters, vol. 384, no. 3, pp. 234-238, 2005.

[26] R. Yang, Z. N. Huang, and J. S. Cheng, "Anticonvulsion effect of acupuncture might be related to the decrease of neuronal and inducible nitric oxide synthases," Acupuncture and ElectroTherapeutics Research, vol. 25, no. 3-4, pp. 137-143, 2000.

[27] Y. H. Chang, M. T. Hsieh, and J. T. Cheng, "Increase of locomotor activity by acupuncture on Bai-Hui point in rats," Neuroscience Letters, vol. 211, no. 2, pp. 121-124, 1996.

[28] Q. Li, J. C. Guo, H. B. Jin, J. S. Cheng, and R. Yang, "Involvement of taurine in penicillin-induced epilepsy and anti-convulsion of acupuncture: a preliminary report," Acupuncture and ElectroTherapeutics Research, vol. 30, no. 1-2, pp. 1-14, 2005.
[29] Z. N. Huang, R. Yang, G. Chen, and J. S. Cheng, "Effect of electroacupuncture and 7-NI on penicillin-induced epilepsy and their relation with intrahippocampal no changes," Acta Physiologica Sinica, vol. 51, no. 5, pp. 508-514, 1999.

[30] J. Guo, J. Liu, W. Fu et al., "The effect of electroacupuncture on spontaneous recurrent seizure and expression of GAD67 mRNA in dentate gyrus in a rat model of epilepsy," Brain Research, vol. 1188, no. 1, pp. 165-172, 2008.

[31] M. L. Bullock, A. J. Umen, P. D. Culliton, and R. T. Olander, "Acupuncture treatment of alcoholic recidivism: a pilot study," Alcoholism: Clinical and Experimental Research, vol. 11, no. 3, pp. 292-295, 1987.

[32] L. Z. Wu, C. L. Cui, J. B. Tian, D. Ji, and J. S. Han, "Suppression of morphine withdrawal by electroacupuncture in rats: dynorphin and $\kappa$-opioid receptor implicated," Brain Research, vol. 851, no. 1-2, pp. 290-296, 1999.

[33] K. Yoshimoto, B. Kato, K. Sakai, M. Shibata, T. Yano, and M. Yasuhara, "Electroacupuncture stimulation suppresses the increase in alcohol-drinking behavior in restricted rats," Alcoholism: Clinical and Experimental Research, vol. 25, no. 6, supplement, pp. 63S-68S, 2001.

[34] R. J. Zhao, S. S. Yoon, B. H. Lee et al., "Acupuncture normalizes the release of accumbal dopamine during the withdrawal period and after the ethanol challenge in chronic ethanol-treated rats," Neuroscience Letters, vol. 395, no. 1, pp. 28-32, 2006.

[35] Y. Chae, C. H. Yang, Y. K. Kwon et al., "Acupuncture attenuates repeated nicotine-induced behavioral sensitization and c-Fos expression in the nucleus accumbens and striatum of the rat," Neuroscience Letters, vol. 358, no. 2, pp. 87-90, 2004.

[36] S. P. Hunt, A. Pini, and G. Evan, "Induction of c-fos-like protein in spinal cord neurons following sensory stimulation," Nature, vol. 328, no. 6131, pp. 632-634, 1987.

[37] J. Buritova, V. Chapman, P. Honoré, and J. M. Besson, “The contribution of peripheral bradykinin B2 receptors to carrageenanevoked oedema and spinal c-Fos expression in rats," European Journal of Pharmacology, vol. 320, no. 1, pp. 73-80, 1997.

[38] H. Nojima, C. T. Simons, J. M. Cuellar, M. I. Carstens, J. A. Moore, and E. Carstens, "Opioid modulation of scratching and spinal c-fos expression evoked by intradermal serotonin," Journal of Neuroscience, vol. 23, no. 34, pp. 10784-10790, 2003.

[39] H. Nojima, J. M. Cuellar, C. T. Simons, M. I. Carstens, and E. Carstens, "Spinal c-fos expression associated with spontaneous biting in a mouse model of dry skin pruritus," Neuroscience Letters, vol. 361, no. 1-3, pp. 79-82, 2004.

[40] R. E. Coggeshall, "Fos, nociception and the dorsal horn," Progress in Neurobiology, vol. 77, no. 5, pp. 299-352, 2005.

[41] M. Clark, R. M. Post, S. R. B. Weiss, and T. Nakajima, "Expression of c-fos mRNA in acute and kindled cocaine seizures in rats," Brain Research, vol. 582, no. 1, pp. 101-106, 1992.

[42] H. Z. Zhang, L. X. Zhang, Y. F. She, W. L. Li, X. J. Zhang, and R. J. Zhang, "Effect of electroacupuncture on apoptosis of hippocampus tissue in mice with vascular dementia," Zhen $\mathrm{Ci}$ Yan Jiu, vol. 33, no. 6, pp. 377-381, 2008.

[43] P. Fallopa, J. C. Escosteguy-Neto, P. Varela, T. N. Carvalho, A. M. Tabosa, and J. G. Santos Jr., "Electroacupuncture reverses ethanol-induced locomotor sensitization and subsequent pERK expression in mice," The International Journal of Neuropsychopharmacology, vol. 15, no. 8, pp. 1121-1133, 2012.

[44] N. Zouhairi, S. Ba-M'hamed, and M. Bennis, "Maternal prenatal stress in rats influences c-fos expression in the spinal cord of the offspring," Acta Histochemica, vol. 114, no. 5, pp. 525-533, 2012. 
[45] S. Inan, N. J. Dun, and A. Cowan, "Nalfurafine prevents $5^{\prime}$ guanidinonaltrindole- and compound 48/80-induced spinal cfos expression and attenuates $5^{\prime}$-guanidinonaltrindole-elicited scratching behavior in mice," Neuroscience, vol. 163, no. 1, pp. 23-33, 2009.

[46] G. C. Brailoiu, S. L. Dun, M. Ohsawa et al., "KiSS-1 expression and metastin-like immunoreactivity in the rat brain," Journal of Comparative Neurology, vol. 481, no. 3, pp. 314-329, 2005.

[47] E. S. Lein, M. J. Hawrylycz, N. Ao et al., "Genome-wide atlas of gene expression in the adult mouse brain," Nature, vol. 445, no. 7124, pp. 168-176, 2007.

[48] M. Gasior, J. T. Ungard, and J. M. Witkin, "Preclinical evaluation of newly approved and potential antiepileptic drugs against cocaine-induced seizures," Journal of Pharmacology and Experimental Therapeutics, vol. 290, no. 3, pp. 1148-1156, 1999.

[49] R. R. Matsumoto, D. L. Gilmore, B. Pouw et al., "Novel analogs of the $\sigma$ receptor ligand BD1008 attenuate cocaine-induced toxicity in mice," European Journal of Pharmacology, vol. 492, no. 1, pp. 21-26, 2004.

[50] W. Vongpatanasin, Y. Mansour, B. Chavoshan, D. Arbique, and R. G. Victor, "Cocaine stimulates the human cardiovascular system via a central mechanism of action," Circulation, vol. 100, no. 5, pp. 497-502, 1999.

[51] J. M. Witkin, B. Levant, A. Zapata, R. Kaminski, and M. Gasior, "The dopamine $\mathrm{D}_{3} / \mathrm{D}_{2}$ agonist (+)-PD-128,907 [(R-(+)-trans3,4a,10b-tetrahydro-4-propyl-2H,5H-[1]benzopyrano[4,3-b]-1, 4-oxazin-9-ol)] protects against acute and cocaine-kindled seizures in mice: further evidence for the involvement of $\mathrm{D}_{3}$ receptors," Journal of Pharmacology and Experimental Therapeutics, vol. 326, no. 3, pp. 930-938, 2008.

[52] B. I. Khodorov, E. G. Vornoitskii, V. B. Ignat'eva, M. R. Mukumov, and G. M. Kitaĭgorodskaia, "Mechanism of uncoupling of excitation and contraction in the myocardial fibres of the frog and guinea pig on blocking the slow sodium-calcium channels with compound D-600," Biofizika, vol. 21, no. 6, pp. 1024-1030, 1976.

[53] G. K. Wang, "Cocaine-induced closures of single batrachotoxinactivated $\mathrm{Na}^{+}$channels in planar lipid bilayers," Journal of General Physiology, vol. 92, no. 6, pp. 747-765, 1988.

[54] M. Naguib, M. M. A. Magboul, A. H. Samarkandi, and M. Attia, "Adverse effects and drug interactions associated with local and regional anaesthesia," Drug Safety, vol. 18, no. 4, pp. 221-250, 1998.

[55] W. Lasoń, "Neurochemical and pharmacological aspects of cocaine-induced seizures," Polish Journal of Pharmacology, vol. 53, no. 1, pp. 57-60, 2001.

[56] A. Mansour and S. J. Watson, "Dopamine receptor expression in the central nervous system," in Psychopharmacology: The Fourth Generation of Progress, F. E. Bloom and D. J. Kupfer, Eds., pp. 207-219, Raven Press, New York, NY, USA, 1995.

[57] B. Lee, S. M. Han, and I. Shim, "Acupuncture attenuates cocaine-induced expression of behavioral sensitization in rats: possible involvement of the dopaminergic system in the ventral tegmental area," Neuroscience Letters, vol. 449, no. 2, pp. 128132, 2009.

[58] L. Chen and M. Xu, "Dopamine $\mathrm{D}_{1}$ and $\mathrm{D}_{3}$ receptors are differentially involved in cue-elicited cocaine seeking," Journal of Neurochemistry, vol. 114, no. 2, pp. 530-541, 2010.

[59] R. L. Brackett, B. Pouw, J. F. Blyden, M. Nour, and R. R. Matsumoto, "Prevention of cocaine-induced convulsions and lethality in mice: effectiveness of targeting different sites on the
NMDA receptor complex," Neuropharmacology, vol. 39, no. 3, pp. 407-418, 2000.

[60] J. I. Morgan and T. Curran, "Stimulus-transcription coupling in the nervous system: involvement of the inducible protooncogenes fos and jun," Annual Review of Neuroscience, vol. 14, pp. 421-451, 1991.

[61] R. E. Harlan and M. M. Garcia, "Drugs of abuse and immediateearly genes in the forebrain," Molecular Neurobiology, vol. 16, no. 3, pp. 221-267, 1998.

[62] A. M. Graybiel, R. Moratalla, and H. A. Robertson, "Amphetamine and cocaine induce drug-specific activation of the c-fos gene in striosome-matrix compartments and limbic subdivisions of the striatum," Proceedings of the National Academy of Sciences of the United States of America, vol. 87, no. 17, pp. 69126916, 1990.

[63] B. Hope, B. Kosofsky, S. E. Hyman, and E. J. Nestler, "Regulation of immediate early gene expression and AP-1 binding in the rat nucleus accumbens by chronic cocaine," Proceedings of the National Academy of Sciences of the United States of America, vol. 89, no. 13, pp. 5764-5768, 1992.

[64] S. T. Young, L. J. Porrino, and M. J. Iadarola, "Cocaine induces striatal c-Fos-immunoreactive proteins via dopaminergic $D_{1}$ receptors," Proceedings of the National Academy of Sciences of the United States of America, vol. 88, no. 4, pp. 1291-1295, 1991.

[65] R. C. Pierce and L. J. M. J. Vanderschuren, "Kicking the habit: the neural basis of ingrained behaviors in cocaine addiction," Neuroscience and Biobehavioral Reviews, vol. 35, no. 2, pp. 212219, 2010.

[66] H. J. Groenewegen and H. W. Berendse, "The specificity of the "nonspecific" midline and intralaminar thalamic nuclei," Trends in Neurosciences, vol. 17, no. 2, pp. 52-57, 1994.

[67] C. D. Young and A. Y. Deutch, "The effects of thalamic paraventricular nucleus lesions on cocaine-induced locomotor activity and sensitization," Pharmacology Biochemistry and Behavior, vol. 60, no. 3, pp. 753-758, 1998.

[68] S. J. Spencer, J. C. Fox, and T. A. Day, “Thalamic paraventricular nucleus lesions facilitate central amygdala neuronal responses to acute psychological stress," Brain Research, vol. 997, no. 2, pp. 234-237, 2004.

[69] A. E. Kelley, B. A. Baldo, and W. E. Pratt, "A proposed hypothalamic-thalamic-striatal axis for the integration of energy balance, arousal, and food reward," Journal of Comparative Neurology, vol. 493, no. 1, pp. 72-85, 2005.

[70] P. J. Hernandez, M. E. Andrzejewski, K. Sadeghian, J. B. Panksepp, and A. E. Kelley, "AMPA/kainate, NMDA, and dopamine $\mathrm{D}_{1}$ receptor function in the nucleus accumbens core: a context-limited role in the encoding and consolidation of instrumental memory," Learning and Memory, vol. 12, no. 3, pp. 285-295, 2005.

[71] A. S. Hamlin, K. J. Clemens, E. A. Choi, and G. P. McNally, "Paraventricular thalamus mediates context-induced reinstatement (renewal) of extinguished reward seeking," European Journal of Neuroscience, vol. 29, no. 4, pp. 802-812, 2009.

[72] M. H. James, J. L. Charnley, E. Jones et al., "Cocaine- and amphetamine-regulated transcript (CART) signaling within the paraventricular thalamus modulates cocaine-seeking behaviour," PLoS ONE, vol. 5, no. 9, Article ID e12980, 2010.

[73] S. Mraovitch and Y. Calando, "Interactions between limbic, thalamo-striatal-cortical, and central autonomic pathways during epileptic seizure progression," Journal of Comparative Neurology, vol. 411, no. 1, pp. 145-161, 1999. 
[74] V. Neugebauer, F. Zinebi, R. Russell, J. P. Gallagher, and P. Shinnick-Gallagher, "Cocaine and kindling alter the sensitivity of group II and III metabotropic glutamate receptors in the central amygdala," Journal of Neurophysiology, vol. 84, no. 2, pp. 759-770, 2000.

[75] D. Zhang, L. Zhang, D. W. Lou, Y. Nakabeppu, J. Zhang, and $\mathrm{M}$. Xu, "The dopamine $\mathrm{D}_{1}$ receptor is a critical mediator for cocaine-induced gene expression," Journal of Neurochemistry, vol. 82, no. 6, pp. 1453-1464, 2002.

[76] N. Hiroi, J. R. Brown, C. N. Haile, H. Ye, M. E. Greenberg, and E. J. Nestler, "FosB mutant mice: loss of chronic cocaine induction of Fos-related proteins and heightened sensitivity to cocaine's psychomotor and rewarding effects," Proceedings of the National Academy of Sciences of the United States of America, vol. 94, no. 19, pp. 10397-10402, 1997.

[77] A. M. Graybiel and R. Moratalla, "Dopamine uptake sites in the striatum are distributed differentially in striosome and matrix compartments," Proceedings of the National Academy of Sciences of the United States of America, vol. 86, no. 22, pp. 9020-9024, 1989.

[78] M. A. Medeiros, N. S. Canteras, D. Suchecki, and L. E. A. M. Mello, "c-Fos expression induced by electroacupuncture at the Zusanli point in rats submitted to repeated immobilization," Brazilian Journal of Medical and Biological Research, vol. 36, no. 12, pp. 1673-1684, 2003.

[79] P. K. Thanos, M. Michaelides, C. W. Ho et al., "The effects of two highly selective dopamine $\mathrm{D}_{3}$ receptor antagonists (SB-277011A and NGB-2904) on food self-administration in a rodent model of obesity," Pharmacology Biochemistry and Behavior, vol. 89, no. 4, pp. 499-507, 2008.

[80] M. C. Ritz, E. J. Cone, and M. J. Kuhar, "Cocaine inhibition of ligand binding at dopamine, norepinephrine and serotonin transporters: a structure-activity study," Life Sciences, vol. 46, no. 9, pp. 635-645, 1990.

[81] R. A. Gillis, Y. M. Hernandez, H. K. Erzouki et al., "Sympathetic nervous system mediated cardiovascular effects of cocaine are primarily due to a peripheral site of action of the drug," Drug and Alcohol Dependence, vol. 37, no. 3, pp. 217-230, 1995.

[82] Z. Li, K. Jiao, M. Chen, and C. Wang, "Effect of magnitopuncture on sympathetic and parasympathetic nerve activities in healthy driver-assessment by power spectrum analysis of heart rate variability," European Journal of Applied Physiology, vol. 88, no. 4-5, pp. 404-410, 2003.

[83] E. Haker, H. Egekvist, and P. Bjerring, "Effect of sensory stimulation (acupuncture) on sympathetic and parasympathetic activities in healthy subjects," Journal of the Autonomic Nervous System, vol. 79, no. 1, pp. 52-59, 2000.

[84] J. S. Han, X. H. Chen, S. L. Sun et al., "Effect of low- and highfrequency TENS on Met-enkephalin-Arg-Phe and dynorphin A immunoreactivity in human lumbar CSF," Pain, vol. 47, no. 3, pp. 295-298, 1991.

[85] J. S. Han, X. Z. Ding, and S. G. Fan, "The frequency as the cardinal determinant for electroacupuncture analgesia to be reversed by opioid antagonists," Sheng Li Xue Bao, vol. 38, no. 5, pp. 475-482, 1986.

[86] J. S. Han, "Acupuncture and endorphins," Neuroscience Letters, vol. 361, no. 1-3, pp. 258-261, 2004.

[87] L. L. Cheng, M. X. Ding, C. Xiong, M. Y. Zhou, Z. Y. Qiu, and Q. Wang, "Effects of electroacupuncture of different frequencies on the release profile of endogenous opioid peptides in the central nerve system of goats," Evidence-Based Complementary and Alternative Medicine, vol. 2012, Article ID 476457, 9 pages, 2012. 


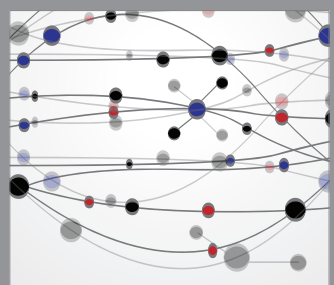

The Scientific World Journal
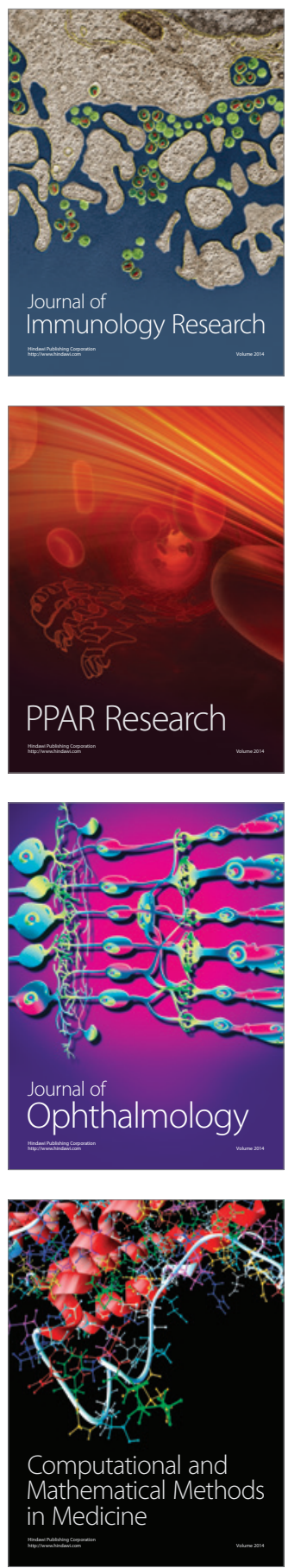

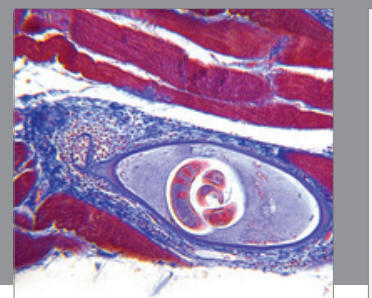

Gastroenterology

Research and Practice
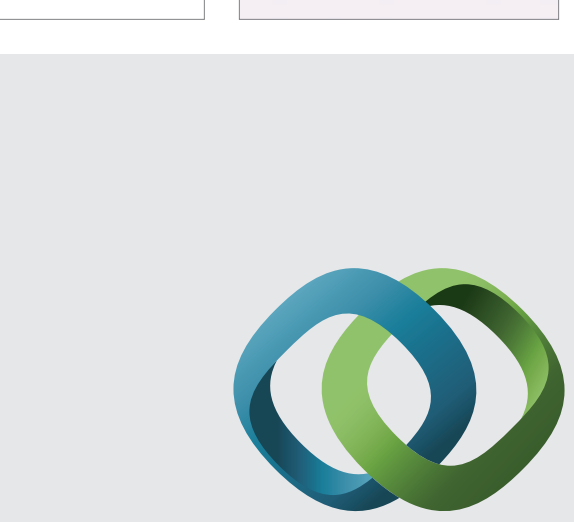

\section{Hindawi}

Submit your manuscripts at

http://www.hindawi.com
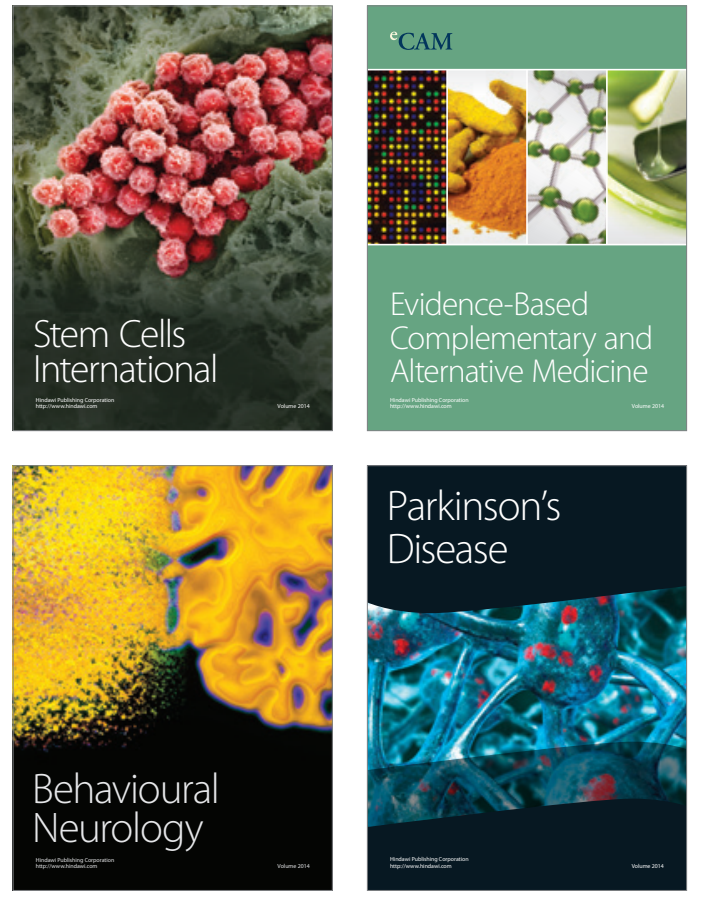
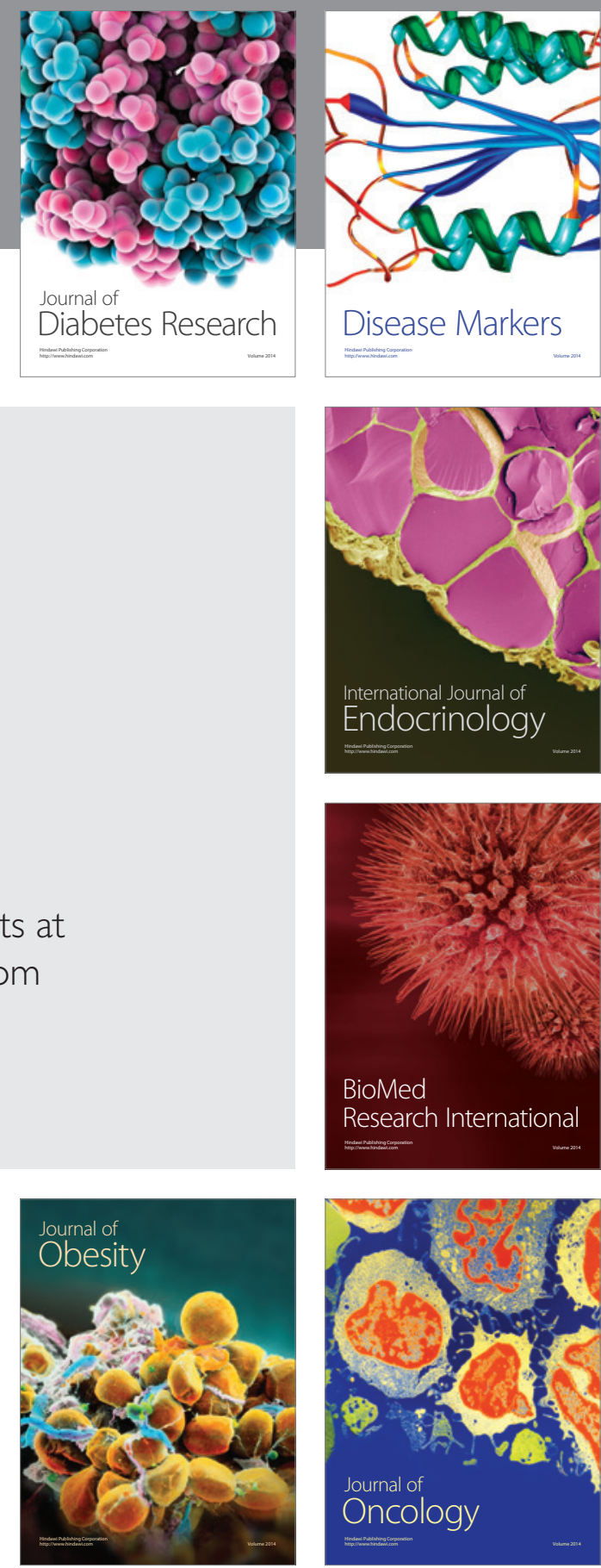

Disease Markers
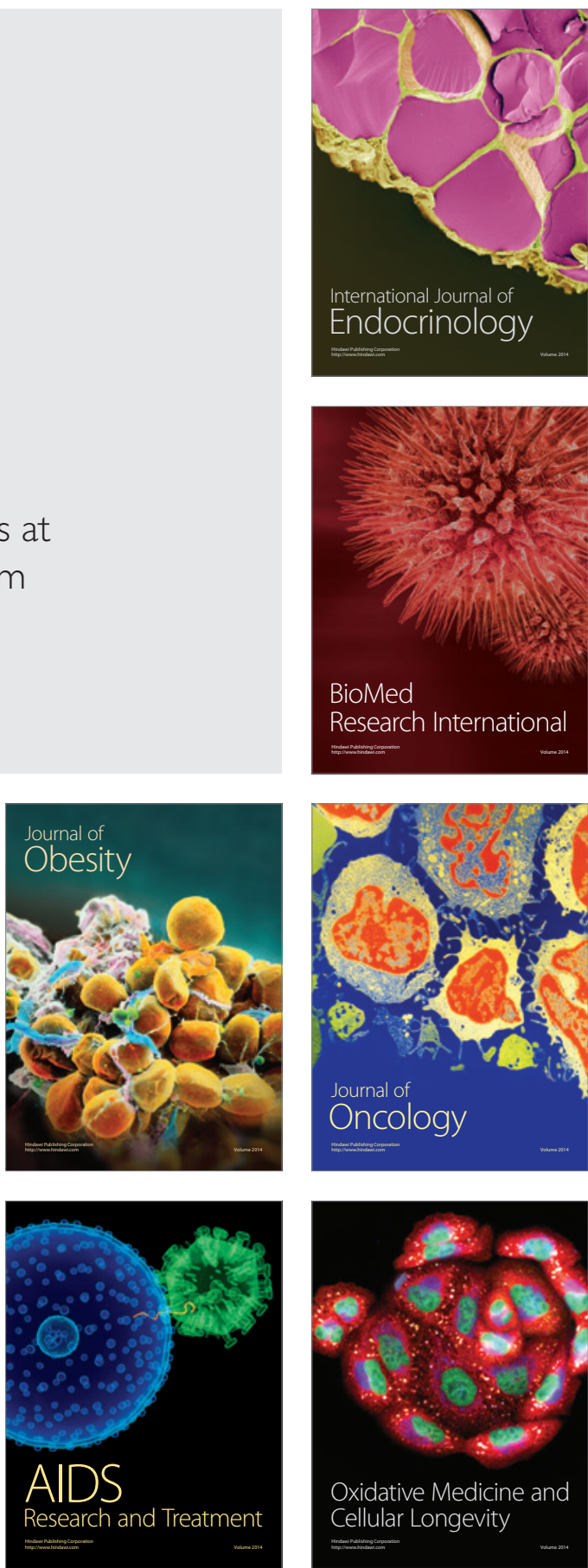